\title{
Defense mechanisms in patients with fibromyalgia and major depressive disorder
}

\author{
Tormod Landmark ${ }^{\star, \star *}$ \\ Tore C Stiles ${ }^{\star, \star * *}$ \\ Egil A Fors ${ }^{*, * \star}$ \\ Are Holen ${ }^{\star, \star \star}$ \\ Petter C Borchgrevink ${ }^{\star, \star \star}$
}

* Centre for Pain and Complex Disorders, St Olav's University Hospital, Trondheim

** Faculty of Medicine, Norwegian University for Science and Technology, Trondheim

*** Department of Psychology, Norwegian University of Science and Technology, Trondheim

NORWAY

\begin{abstract}
Background and objectives: Fibromyalgia (FM) and depression has been suggested to share a common underlying etiology. Few studies have investigated the role of emotional regulation processes in FM compared to depressive disorders. The purpose of the current study was to explore the use of defense mechanisms in FM patients with and without comorbid lifetime depressive disorder (LDD), and to compare their use of defenses to healthy control subjects and patients with Major Depressive Disorder (MDD).

Methods: A total of 91 participants were included (17 with FM and LDD, 25 with FM but not LDD, 24 with MDD, and 25 healthy controls). Depressive disorders were identified by using the Structured Clinical Interview for DSM Axis I disorders (SCID-I). All diagnosis of FM were confirmed to meet the American College of Rheumatology's criteria for FM. The Life Style Index (LSI) was used to measure defense mechanisms.

Results and Conclusions: Group comparisons indicated that MDD patients and FM patients with LDD made significantly more use of defenses than healthy controls, whereas FM patients without LDD made significantly less use of defenses than both MDD patients and FM patients with LDD, but did not differ from healthy controls. Follow up analyses indicated significant main effects for the defense mechanisms of regression, compensation and displacement. This study suggests that FM and depression do not share common risk factors in terms of restricted affects or avoidance of conflicted feelings.
\end{abstract}




\section{Introduction}

Fibromyalgia (FM) is defined by chronic, widespread pain and generalized elevated sensitivity to palpations in 11 or more of 18 localized tender points ${ }^{1}$. In the general population, prevalence rates of $3.4 \%$ for women and $0.5 \%$ for men have been estimated ${ }^{2}$. The etiology of FM is unknown, and the presented complaints are overlapping with those of other unexplained medical syndromes such as chronic fatigue and irritable bowl syndrome $^{3}$. High concurrent prevalence rates of depression in FM populations ${ }^{4}$ and coaggregations of depression and FM in families ${ }^{5}$ suggest shared etiologies and common familial risk factors for the two disorders ${ }^{6}$.

Few studies have explored the mechanisms for emotional regulation of chronic pain compared to depression ${ }^{7}$. Inabilities to modulate or express intense, unacceptable feelings have been proposed as shared risks for both chronic pain and depression ${ }^{8}$. Moreover, restricted affects or avoidance of conflicted feelings have been shown to relate to increased pain and disability ${ }^{9}$. On the contrary, relief from pain might be obtained by emotional disclosure ${ }^{10}$. Accordingly, repressed, inhibited and denied negative emotions might have profound impact on how pain is experienced, interpreted and communicated by the individual.

Current definitions of defense mechanisms highlight their function in emotional regulation processes. They are assumed to modify conscious experience, thoughts and affects in response to stressors and painful events. Several attempts have been made to classify defense mechanisms in levels according to their maturity and adaptive value. Vaillant ${ }^{11}$ conceptualized four levels of maturity ranging from psychotic to immature, neurotic and mature defenses. The level of defensive func- tioning has been shown to relate to affective disorders $^{12}$, personality disorders ${ }^{13}$ as well as to healthy functioning ${ }^{14}$.

Previously the relationship between chronic pain and defense has been studied by using the Minnesota Multiphasic Personality Inventory (MMPI) ${ }^{15}$ and its successor, MMPI- $2^{16}$. Several authors have argued that MMPI profiles with elevated scores on scale 1 (hypochondrias) and scale 3 (hysteria) compared to scale 2 (depression), indicate channeling of emotional problems into somatic concerns. Hence, this has been referred to as the conversion V profile. Graham ${ }^{16}$ claimed that patients with this profile excessively use defense mechanisms such as denial, projection and rationalization. The conversion $\mathrm{V}$ profile is disputed, however, since illness severity or somatic distress rather than defensive functioning may be expressed ${ }^{17}$. In detecting defense mechanisms in patients with chronic pain, items unrelated to bodily symptoms and health complaints are therefore preferable. Tauschke and collaborators ${ }^{18}$ found chronic pain patients different from psychiatric patients in terms of defense mechanisms. The authors concluded that chronic pain is not associated with psychological defense mechanisms. However, they had no healthy control group. Another study ${ }^{19}$ reported that rationalization and regression predicted poor outcome of discectomy in low back pain patients, whereas coping mechanisms did not.

Few studies have explored the use of psychological defense mechanisms in patients with fibromyalgia. Leviatt et al. ${ }^{20}$ concluded that FM patients used dissociation far more than patients with rheumatoid arthritis. Some studies on alexithymia, a construct related to defense ${ }^{21}$ have suggested that difficulties in identifying feelings are characteristic of FM patients $^{22}$. Other studies have shown disparate findings ${ }^{23}$. 
The aim of the current study was twofold. Firstly, we wanted to explore whether or not patients with FM rely more excessively on defense mechanisms compared to healthy controls, and secondly, we wanted to explore whether or not patients with FM use defense mechanisms similarly to patients with major depressive disorder. Due to high rates of depressive disorders among fibromyalgia patients, we wanted to investigate these relationships separately for those FM patients with a co morbid lifetime depressive disorder and those without a comorbid lifetime depressive disorder.

\section{Method}

\section{Participants}

The sample included 91 participants recruited from three different sites. Fortytwo FM patients came mainly from the local Association of Fibromyalgia. Out of the 42 participants in the fibromyalgia group, 17 $(40,5 \%)$ also met the criteria for lifetime depressive disorder (LDD). We chose to divide this group in two, i.e. 17 patients meeting the criteria for both LDD and FM and 25 patients meeting the criteria for FM but not LDD. Twenty-four patients meeting the criteria for non-psychotic major depressive disorder (MDD) came from a general psychiatric outpatient clinic. A control group of 25 voluntary women was recruited among cleaners at the University Hospital in Trondheim, and among nurse assistants at a local nursing home. None of which had higher level education ( $>12$ years). All groups consisted exclusively of women. Mean age was 47.2 years for the FM group without LDD (range 23 - 69), 46.7 years for FM patients with LDD (range 28 - 63), 45.2 years for the healthy control group (range
25-58) and 38, 5 years for the MDD group (range 23-49 years).

\section{Procedure}

FM diagnoses were confirmed by a specialist in physical medicine. All FM patients were evaluated to meet the American College of Rheumatology's criteria for $\mathrm{FM}^{1}$. Moreover, all participants, except the controls, were diagnosed with the Structured Clinical Interview for DSM Axis I disorders $(\text { SCID-I })^{24}$. A trained psychologist (T.S.) conducted the interviews. Audio or videotaped interviews of a diagnostically mixed group of randomly selected patients $(\mathrm{N}=30)$ were observed and rated by a second diagnostician. The inter-rater reliability was assessed by a paired rater design. Kappa values for a lifetime diagnosis of depressive disorder were 0.92 .

The control subjects did not undergo diagnostic evaluations but were screened for widespread pain by self report using the Brief Pain Inventory ${ }^{25}$ and for depression using Beck's depression inventory ${ }^{26}$. A total of 50 questionnaires were handed out, and $31(62 \%)$ were returned. Six control subjects were excluded due to reports of widespread chronic pain or because they scored above cut off $(<9)$ indicating mild depression on BDI. Accordingly, a total of 25 participants remained as control subjects. An overview of the recruitment and assessment procedure for each group is illustrated in figure 1 .

\section{Measurement}

The Life Style Index (LSI) ${ }^{27}$ was used to identify defense mechanisms. This self report instrument was initially developed on the basis of Plutchik's theory of emotions 
Recruitment site and assessment methods

\begin{tabular}{|c|c|c|c|}
\hline & $\begin{array}{l}\text { FMS Patients: } \\
\quad \mathrm{N}=42\end{array}$ & $\begin{array}{l}\text { Patients with MDD: } \\
\qquad \mathrm{N}=25\end{array}$ & $\begin{array}{l}\text { Healthy control group } \\
\qquad \mathrm{N}=25\end{array}$ \\
\hline Requited from: & $\begin{array}{l}\text { Local association of } \\
\text { Fibromyalgia in Trondheim }\end{array}$ & $\begin{array}{l}\text { A general psychiatric } \\
\text { outpatient clinic } \\
\text { in Trondheim }\end{array}$ & $\begin{array}{l}\text { Cleaners at the St Olavs } \\
\text { Hospital } \\
\text { Nurse assistants at a } \\
\text { local nursing home }\end{array}$ \\
\hline Assessment of Pain: & $\begin{array}{l}\text { Evaluated with tender } \\
\text { point examination }\end{array}$ & & Brief Pain inventory \\
\hline $\begin{array}{l}\text { Assessment of } \\
\text { depression: }\end{array}$ & $\begin{array}{l}\text { Psychiatric diagnostic } \\
\text { interview }\end{array}$ & $\begin{array}{l}\text { Psychiatric diagnostic } \\
\text { interview }\end{array}$ & $\begin{array}{l}\text { Beck Depression } \\
\text { inventory }\end{array}$ \\
\hline $\begin{array}{l}\text { Assessment of } \\
\text { Defense: }\end{array}$ & Life style Index & Life style Index & Life style Index \\
\hline
\end{tabular}

Figure 1: Overview of the recruitment and assessment for each group.

holding that psychological defenses are related to specific affect states, and also, to diagnostic concepts. The following defense mechanisms are included: Compensation, denial, displacement, intellectualization (including undoing, sublimation and rationalization), projection, reaction formation, regression (including acting out and fantasy) and repression (including introjections and isolation). A total score, summing up all positive responses is also included, indicating an overall defensive functioning. The score on each scale were divided by the total number of items for every scale before estimating the mean. The validity of LSI has been demonstrated by positive correlations with anxiety for every scale except denial, and negative correlations with self esteem scorers ${ }^{27}$. Studies having used the LSI indicate that depressed patients use more immature and intermediate level defense mechanisms than non-patients and the total score has been found to distinguish psychiatric inpatients from normal controls ${ }^{28}$. The regression scale has been reported to distinguish successfully suicidal from non-suicidal patients ${ }^{29}$ and normal adolescents from adolescent psychiatric patients ${ }^{30}$. Studies having used the LSI indicate that depressed patients $^{28}$ as well as patients with partial eating disorders ${ }^{31}$ use more immature (regression) and intermediate level (compensation and displacement) defense mechanisms than non-patients. The Norwegian translation of LSI has demonstrated the same psychometric properties as the original test. Internal reliabilities of the Norwegian scales are moderate while 'test-retest' scores are highly correlated ${ }^{32}$.

\section{Statistics}

Total defense score seemed to follow a normal distribution. Each specific defense mechanism where also tested for normality and seemed by large to follow a normal distribution but with some being slightly skewed towards left. Analysis of covariance (ANCOVA) with age as a covariate and total defense mechanisms score as the dependent variable was carried out to detect overall differences in the use of defense mechanisms between the four groups. Thereafter ANCOVAs with age as a covariate and each of the specific defense mechanisms as 
dependent variables were conducted. Significant four groups ANCOVAs were then followed up with two group ANCOVA comparisons to detect which of the groups where different. All statistics were carried out by using SPSS version 13 for Windows. Due to the explorative nature of this study, a liberal $p=0.05$ was considered statistically significant.

\section{Results}

An overall difference in terms of age was obtained between the groups by using oneway ANOVA $\left(\mathrm{F}_{(3,88)}=4.33, p<0.01\right)$. Post hoc Bonnferoni comparisons revealed that the MDD group was younger than both the FM group with LDD, and the FM group without LDD $(p<0.05$ and $p<0.01$ respectively)

The mean and standard deviation of the various defense mechanisms are presented in Table I. Projection was the most frequent- ly reported defense mechanism for every group, followed by intellectualization and reaction formation. Regression and displacement were the least used defense mechanism among the healthy controls and FM patients without comorbid LDD, whereas MDD patients made least use of compensation, and FM patients with LDD made least use of displacement.

Overall analysis of covariance revealed significant differences between the four groups in the total use of defense mechanisms $\left(\mathrm{F}_{(3,86)}=4.11, p<0.01\right)$ when adjusting for age. Post hoc two-group ANCOVA comparisons with age as a covariate indicated that the LSI total score distinguished between healthy control subjects and MDD patients $\left(\mathrm{F}_{(1,46)}=5.15, p<0.05\right)$, as well as between healthy control subjects and FM patients with $\operatorname{LDD}\left(\mathrm{F}_{(1,37)}=7.92 p<0.05\right)$. Moreover, FM patients with LDD made significantly more total use of defense mechanisms compared to FM patients without $\operatorname{LDD}\left(\mathrm{F}_{(1,37)}=3.82, p=0.05\right)$.

Table I

Means and standard deviations for defense mechanisms on the LSI for all four groups

\begin{tabular}{|c|c|c|c|c|c|c|c|c|}
\hline \multirow[b]{3}{*}{ Defense mechanisms } & \multicolumn{4}{|c|}{ Fibromyalgia } & \multirow{2}{*}{\multicolumn{2}{|c|}{$\begin{array}{c}\text { Major Depressive } \\
\text { Disorder } \\
(\mathrm{N}=24)\end{array}$}} & \multirow{2}{*}{\multicolumn{2}{|c|}{$\begin{array}{l}\text { Healthy } \\
\text { controls } \\
(\mathrm{N}=25)\end{array}$}} \\
\hline & \multicolumn{2}{|c|}{$\begin{array}{l}\text { With LDD } \\
(\mathrm{N}=17)\end{array}$} & \multicolumn{2}{|c|}{$\begin{array}{l}\text { Without LDD } \\
\qquad(\mathrm{N}=25)\end{array}$} & & & & \\
\hline & M & (SD) & M & (SD) & M & (SD) & M & (SD) \\
\hline Total Score & 0.38 & $(0.09)^{\mathrm{a}}$ & 0.33 & $(0.09)^{\mathrm{c}}$ & 0.37 & $(0.06)^{\mathrm{a}}$ & 0.30 & $(0.09)$ \\
\hline Repression & 0.37 & $(0.18)$ & 0.37 & $(0.19)$ & 0.38 & $(0.18)$ & 0.31 & $(0.18)$ \\
\hline Regression & 0.28 & $(0.15)^{\mathrm{a}}$ & 0.19 & $(0.14)^{\mathrm{b}}$ & 0.33 & $(0.15)^{\mathrm{a}}$ & 0.14 & $(0.10)$ \\
\hline Compensation & 0.37 & $(0.23)^{\mathrm{ab}}$ & 0.24 & $(0.22)$ & 0.20 & $(0.14)$ & 0.24 & $(0.15)$ \\
\hline Projection & 0.54 & $(0.18)$ & 0.46 & $(0.16)$ & 0.51 & $(0.14)$ & 0.51 & $(0.18)$ \\
\hline Displacement & 0.24 & $(0.18)^{\mathrm{a}}$ & 0.17 & $(0.13)$ & 0.27 & $(0.14)^{\mathrm{a}}$ & 0.14 & $(0.14)$ \\
\hline Intellectualization & 0.49 & $(0.12)$ & 0.42 & $(0.15)$ & 0.46 & $(0.15)$ & 0.40 & $(0.12)$ \\
\hline Reaction Formation & 0.51 & $(0.20)$ & 0.44 & $(0.22)$ & 0.42 & $(0.21)$ & 0.36 & $(0.20)$ \\
\hline Denial & 0.32 & $(0.11)$ & 0.37 & $(0.18)$ & 0.37 & $(0.17)$ & 0.35 & $(0.15)$ \\
\hline
\end{tabular}

LDD = Lifetime Depressive Disorder

${ }^{\mathrm{a}} \mathrm{p}<0.05$ compared to Healthy Control

${ }^{\mathrm{b}} \mathrm{p}<0.05$ compared to MDD

${ }^{c} \mathrm{p}=0.05$ compared to FM with LDD 
In terms of specific defense mechanisms significant main effects were found in terms of regression $\left(\mathrm{F}_{(3,86)}=8.05, p<0.001\right)$, compensation $\left(\mathrm{F}_{(3,86)}=3.51, p<0.05\right)$ and displacement $\left(\mathrm{F}_{(3,86)}=2.59, p=0.05\right)$. MDD patients differed from control subjects in the use of regression $\left(\mathrm{F}_{(1,46)}=19.95, p<0.001\right)$ and displacement $\left(\mathrm{F}_{(1,46)}=5.27, p<0.05\right)$. FM patients with LDD also made significantly more use of regression $\left(\mathrm{F}_{(1,37)}=11.12\right.$, $p<0.01)$ and displacement $\left(\mathrm{F}_{(1,37)}=4.36, p\right.$ $<0.05)$ compared to healthy controls. Moreover, they made significantly more use of compensation compared to both healthy controls $\left(\mathrm{F}_{(1,37)}=3.92, p<0.05\right)$, and MDD patients $\left(\mathrm{F}_{(1,38)}=5.52, p<0.05\right)$. FM patients without LDD did not differ from healthy controls in the use of any defense mechanisms. They made significantly less use of regression compared to MDD patients $\left(\mathrm{F}_{(1,46)}=7.51\right.$, $p<0.01$ ), however. No specific defense mechanisms significantly distinguished between the two FM groups, but FM patients with LDD displayed a tendency towards more use of regression $\left(\mathrm{F}_{(1,37)}=3.47\right.$, $p=0.07)$. All significant group differences are indicated in Table I.

\section{Discussion}

The aim of this study was to assess the use of defense mechanisms in FM patients with and without a comorbid lifetime depressive disorder, and to compare them to major depressed patients and healthy controls. Our main findings indicated that healthy controls had a lower overall defense score compared to both MDD patients and FM patients with LDD. Moreover FM patients with LDD differed from FM patients without LDD on the total score. FM patients without LDD did not differ from the control group, however.
Use of specific defense mechanisms such as compensation, displacement and regression was significantly associated with meeting the criteria for a depressive disorder. These findings are in accordance with previous findings ${ }^{28}$. Moreover, these findings are accounted for by theory implying that the use of defense mechanisms corresponds to the degree of psychopathology ${ }^{27}$. The most significant association was found for regression. Regression has been referred to as representing the least adaptive defense mechanisms in LSI ${ }^{28}$. Accordingly increased use of immature defense mechanisms may be accounted for by meeting the criteria for a depressive disorder.

The current study demonstrates that FM was not associated with increased use of defense mechanisms when comorbidity of a depressive disorder was accounted for. Consequently, excessive use of defense mechanisms does not seem to be a shared risk factor for FM and depression. Restricted affects and avoidance of conflicted feelings is related to depression, but not FM. Distinctions may thus be drawn between FM patients with and without comorbid lifetime depressive disorders in the use of defense mechanisms. Meeting the criteria for FM does not imply inflexible or pathological psychological functioning per se. Diagnosing depressive disorders, or any other psychopathology, is therefore essential in accounting for psychological functioning and emotional regulation of FM patients. These findings also underscore the fact that without any evidence of psychological illness, FM should not be attributed to hidden psychological causes.

A methodological advance of the present study compared to those using the MMPI is that an instrument specifically designed to measure defense mechanisms was used. However, the internal consistencies and specificity of the LSI scales have been criti- 
cized $^{32}$. Conte \& Apter ${ }^{28}$ admits that some degree of internal consistency had to be sacrificed when combining defense mechanisms into single scales because they are abstract concepts. Plutchik ${ }^{27}$ claimed that limited internal consistencies simply reflect the multidimensionality of the constructs. We therefore chose to use the total defense score in the initial analyses to give a general estimation of differences between the four groups in terms of defensive functioning. This is in line with other studies showing the empirical value of overall defensive functioning ${ }^{33}$. On a general basis, self report measures of defense has been criticized for lack of validity ${ }^{34}$. In terms of the individual defense mechanisms, our findings should therefore be interpreted with caution. The current study should be regarded as explorative in terms of specific defense mechanisms, and further studies using observer rated measures of defense may be required to investigate the relationships more closely. Since there seemed to be a slight deviation from normality in the distribution of compensation, displacement and repression, the ANOVA statistics should also be considered with caution for these analyses.

Defense mechanisms are regarded as relatively stable and lasting characteristics of individuals. Accordingly, their nature might be associated with FM independent of current depressive episodes. Moreover, previous episodes of depression have been claimed to predispose some individuals towards chronic pain disorders ${ }^{35}$. We therefore chose to account for a lifetime episode of depression when assessing the relationship between FM and defense mechanisms. The diagnostic assessment of lifetime depressive disorder is based on retrospective reporting of symptoms, which may reduce the reliability of the diagnoses. On the other hand, the high inter-rater reliabili- ty suggests that the diagnoses were adequately obtained. Previous episodes of depression were not accounted for in the healthy control group, however, as they were screened for depressive symptoms and pain by using self-report instruments.

We did not account for severity of pain, stiffness or any other specific FM related symptoms. It might be argued that FM patients with a comorbid depressive disorder constitute a more severely affected sub-group of FM and that increased use of defenses may be attributed to the severity of FM. However, depression seem to be a risk factor for elevated functional limitations independent of pain intensity ${ }^{36}$, and it is unlikely that defense mechanisms should be more strongly related to pain intensity than other functional outcome measures among FM patients.

Finally, a limitation of the current study is related to the moderate sample size $(\mathrm{N}=91)$ and that recruitments were conducted at different sites. Relatively large standard deviations for specific defense mechanisms indicates that more precise estimates would be obtained by increasing the sample size, thus, reducing the sample error. The fact that MDD patients were recruited from tertiary care, whereas FM patients were not, might have contributed to differences in the severity of the cases included. That is, the MDD patients in our sample might have represented more severe cases than the FM patients.

In conclusion, this study did not support the notion that FM is associated with extensive use of defense mechanisms. Depressive disorder, however, was highly associated with defense mechanisms. Major distinctions seem to exist between those FM patients who meet the criteria for lifetime depressive disorder and those who do not in terms of defensive functioning. 


\section{References}

1. Wolfe F, Smythe HA, Yunus MB, Bennett RM, Bombardier C, Goldenberg DL, et al. The American College of Rheumatology 1990 Criteria for the Classification of Fibromyalgia. Report of the Multicenter Criteria Committee. Arthritis Rheum 1990; 33(2): 160-172.

2. Wolfe F, Ross K, Anderson J, Russell IJ, Hebert L. The prevalence and characteristics of fibromyalgia in the general population. Arthritis Rheum 1995; 38(1): 19-28.

3. Wessely S, Hotopf M. Is fibromyalgia a distinct clinical entity? Historical and epidemiological evidence. Baillieres Best Pract Res Clin Rheumatol 1999; 13(3): 427-436.

4. Epstein SA, Kay G, Clauw D, Heaton R, Klein D, Krupp L, et al. Psychiatric disorders in patients with fibromyalgia. A multicenter investigation. Psychosomatics 1999; 40(1): 57-63.

5. Hudson JI, Arnold LM, Keck PE, Jr, Auchenbach MB, Pope HG, Jr. Family study of fibromyalgia and affective spectrum disorder. Biol Psychiatry. 2004 1; 56(11): 884-891.

6. Raphael KG, Janal MN, Nayak S, Schwartz JE, Gallagher RM. Familial aggregation of depression in fibromyalgia: a community-based test of alternate hypotheses. Pain. 2004; 110(1-2): 449-460.

7. Keefe FJ, Lumley M, Anderson T, Lynch T, Studts JL, Carson KL. Pain and emotion: new research directions. J Clin Psychol. 2001; 57(4): 587-607.

8. Beutler LE, Engle D, Oro'-Beutler ME, Daldrup R, Meredith K. Inability to express intense affect: a common link between depression and pain? J Consult Clin Psychol 1986; 54(6): 752-759.

9. Burns JW, Kubilus A, Bruehl S, Harden RN. A fourth empirically derived cluster of chronic pain patients based on the multidimensional pain inventory: evidence for repression within the dysfunctional group. J Consult Clin Psychol 2001; 69(4): 663-673.

10. Smyth JM, Stone AA, Hurewitz A, Kaell A. Effects of writing about stressful experiences on symptom reduction in patients with asthma or rheumatoid arthritis: a randomized trial. JAMA 1999 14; 281(14): 1304-1309.

11. Vaillant GE. Ego Mechanisms of Defense: A Guide for Clinicians and Researchers. Washington DC: American Psychiatric Press; 1992.

12. Vaillant GE, Drake RE. Maturity of ego defenses in relation to DSM-III axis II personality disorder. Arch Gen Psychiatry 1985; 42(6): 597-601.
13. Vaillant GE. Ego mechanisms of defense and personality psychopathology. J Abnorm Psychol 1994; 103(1): 44-50.

14. Vaillant GE. Adaptive mental mechanisms. Their role in a positive psychology. Am Psychol 2000; 55(1): 89-98.

15. Hathaway S, McKinley J. The Minnesota Multiphasic Personality Inventory. Minneapolis: University of Minnesota Press; 1943.

16. Graham J. MMPI-2 Assessing personality and psychopatology. Oxford, England: Oxford University Press; 1993.

17. Keller L, Butcher N. Assesment of chronic pain patients with the MMPI-2. Minneapolis: University of Minnesota Press; 1991.

18. Tauschke E, Merskey H, Helmes E. Psychological defence mechanisms in patients with pain. Pain 1990; 40(2): 161-170.

19. Fulde E, Junge A, Ahrens S. Coping strategies and defense mechanisms and their relevance for the recovery after discectomy. J Psychosom Res 1995; 39(7): 819-826.

20. Leavitt F, Katz RS, Mills M, Heard AR. Cognitive and dissociative manifestations in fibromyalgia. J Clin Rheumatol 2002; 8(2): 77-84.

21. Parker JD, Taylor GJ, Bagby RM. Alexithymia: relationship with ego defense and coping styles. Compr Psychiatry $1998 ; 39(2)$ : 91-98.

22. Sayar K, Gulec H, Topbas M. Alexithymia and anger in patients with fibromyalgia. Clin Rheumatol 2004; 23(5): 441-448.

23. Malt EA, Olafsson S, Lund A, Ursin H. Factors explaining variance in perceived pain in women with fibromyalgia. BMC Musculoskelet Disord 2002 25; 3: 12.

24. Spitzer RL, Williams JB, Gibbon M, First MB. The Structured Clinical Interview for DSM-III-R (SCID). I: History, rationale, and description. Arch Gen Psychiatry 1992; 49(8): 624-629.

25. Cleeland C. Pain assessment in cancer. In: D O, editor. Effects of cancer on qulity of life. Boca Raton: CRC Press; 1991.

26. Beck AT, Ward CH, Mendelson M, Mock J, Erbaugh J. An inventory for measuring depression. Arch Gen Psychiatry $1961 ; 4: 561-571$.

27. Plutchik R, H. K, Conte H. A structural theory of ego defenses and emotions. In: Izard C, editor. Emotions in personality and psychopatology. New York: Plenum Press; 1979. 
28. Conte H, Apter A. The Life Style Index. A SelfReport Measure of Ego Defenses. In: Conte H, Plutchik R, editors. Ego Defenses: Theory and Measurement. New York: Wiley; 1995.

29. Apter A, Plutchik R, Sevy S, Korn M, Brown S, van Praag H. Defense mechanisms in risk of suicide and risk of violence. Am J Psychiatry 1989; 146(8): 1027-1031.

30. Offer R, Lavie R, Gothelf D, Apter A. Defense mechanisms, negative emotions, and psychopathology in adolescent inpatients. Compr Psychiatry 2000; 41(1): 35-41.

31. Stein D, Bronstein Y, Weizman A. Defense mechanisms in a community-based sample of female adolescents with partial eating disorders. Int J Psychiatry Med 2003; 33(4): 343-355.

32. Endresen IM. A Norwegian translation of the Plutchik questionnaire for psychological defense. Scand J Psychol 1991; 32(2): 105-113.

33. Perry JC, Hoglend P. Convergent and discriminant validity of overall defensive functioning. J Nerv Ment Dis 1998; 186(9): 529-535.
34. Mehlman E, Slane S. Validity of Self-Report Measures of Defense Mechanisms. Assessment 1994; 1(2): 189-198.

35. Magni G, Moreschi C, Rigatti-Luchini S, Merskey $\mathrm{H}$. Prospective study on the relationship between depressive symptoms and chronic musculoskeletal pain. Pain 1994; 56(3): 289-297.

36. Okifuji A, Turk DC, Sherman JJ. Evaluation of the relationship between depression and fibromyalgia syndrome: why aren't all patients depressed? J Rheumatol 2000; 27(1): 212-219.

\author{
Address for correspondence: \\ Tormod Landmark \\ St Olavs University Hospital \\ Centre for Pain and Complex Disorders \\ Eirik Jarls gt 10 \\ 7006 Trondheim \\ Norway \\ Phone: +4773868766 / fax +4773866990 \\ tormod.landmark@ntnu.no
}




\section{Linguistics \& Language Behavior Abstracts}

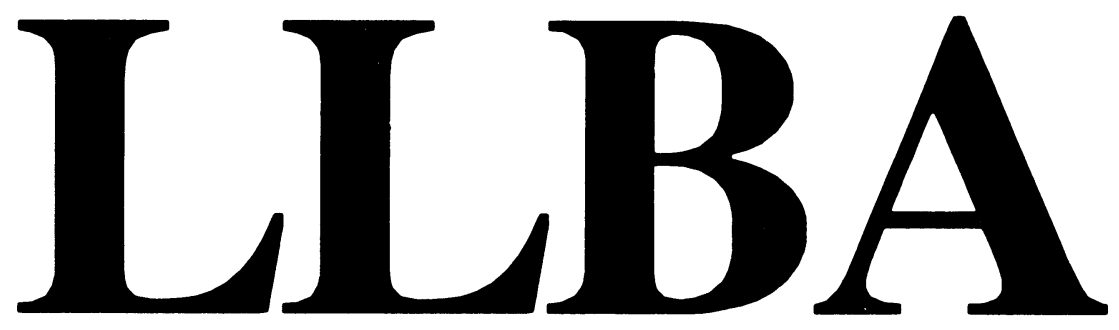

Now entering our 26 th year $(135,000$ abstracts to date) of senvice to linguists and language researchers worldwide. LLBA is available in print and also online from BRS and Dialog.

Linguistics \& Language Behavior Abstracts

$$
\text { P.O. Box } 22206
$$

San Diego, CA 92192-0206

Phone (619) 695-8803 FAX (619) 695-0416

Fast, economical document delivery available. 